\title{
Macrophage heterogeneity and renin-angiotensin system disorders
}

Mark D. Wright ${ }^{1}$, Katrina J. Binger ${ }^{2} *$

${ }^{1}$ Department of Immunology, Monash University, Prahran, Victoria, Australia

${ }^{2}$ Department of Biochemistry and Molecular Biology, Bio21 Institute of Molecular Science and Biotechnology, University of Melbourne, Parkville, Victoria, Australia

*correspondence to: (E) katrina.binger@ unimelb.edu.au (T) +61 383442351

\begin{abstract}
Macrophages are heterogeneous innate immune cells which are important in both the maintenance of tissue homeostasis, and its disruption, by promoting tissue inflammation and fibrosis. The reninangiotensin system is central to the pathophysiology of a large suite of diseases, which are driven in part by large amounts of tissue inflammation and fibrosis. Here, we review recent advances in understanding macrophage heterogeneity in origin and function, and how these may lead to new insights into the pathogenesis of these chronic diseases.
\end{abstract}

Keywords: monocyte, tissue resident macrophage, inflammation, fibrosis, hypertension 


\section{Introduction}

Inflammation and wound healing are essential biological processes activated in response to alterations in tissue homeostasis [60]. Inflammation is necessary to eliminate infiltrated pathogens or damaged cells, recruit other immune cells to the site of damage and, if necessary, activate adaptive immunity. Conversely, wound healing involves the regeneration of cells and deposition of extracellular matrix proteins such as collagen, to enhance barrier reformation and organ repair. Under homeostatic conditions, inflammation and wound healing are balanced, resulting in, for example, the efficient removal of the pathogen without excessive destruction to the surrounding tissue, restoration of the barrier, and repair of organ function. However, when inflammation and/or wound healing are not appropriate, this can quickly manifest into loss of organ function and disease [9]. In situations of excessive or unresolved chronic inflammation, large numbers of leucocytes are recruited to the tissue, releasing cytokines and reactive oxygen species that cause non-specific damage to the tissue. By contrast, when repair processes are abnormal, excessive deposition of collagen can result in remodelling of the extracellular matrix, formation of scar and organ failure [59].

Key elements of both inflammation and wound healing are mediated by innate immune cells known as macrophages [60]. Macrophages are a phagocytic, mononuclear, innate immune cell type with important and extremely diverse roles in responding to infection, promoting inflammation, wound repair and maintaining tissue homeostasis. Understanding the drivers and regulators of macrophage function, and more importantly, how this can go awry and lead to aberrant inflammation and fibrosis, is of key interest to researchers of many disciplines. Here, we review recent studies which have increased knowledge of the complexity and heterogeneity of macrophage cellular biology. We then address the role of macrophages in the development of chronic diseases related to the renin-angiotensin system, and how these new insights into macrophage cellular biology may shed light on these disorders.

\section{Macrophages Function(s)}

Macrophages are perhaps best characterised by their pro-inflammatory role in anti-pathogen immunity [39]. Located in every tissue in the body, together with their cousins, the dendritic cells, they are often referred to as the 'sentinels of the immune system', due to their ability to distinguish self from not self and clear foreign microorganisms by phagocytosis. Macrophages are usually the first immune cells to respond to infection, and they express a diversity of pattern recognition receptors that recognise both conserved structures common to many pathogens (Pathogen Associated Molecular Patterns - PAMPS) and also endogenous biomolecules released only by 
damaged, stressed, and dying cells (Damage Associated Molecular Patterns - DAMPS). Macrophages respond to these stimuli by secreting chemokines and pro-inflammatory cytokines such as IL-1 $\beta$, TNF and IL-6, which collectively activate and recruit other leucocytes to the site of infection/inflammation in order to combat infection [39]. Moreover, macrophages are professional antigen presenting cells and engage in a bi-directional dialogue with $\mathrm{T}$ lymphocytes of the adaptive immune system. Whilst generally considered to lack the ability to initiate naïve $\mathrm{T}$ lymphocyte responses [54], they can amplify existing $\mathrm{T}$ cell responses and steer the differentiation of $\mathrm{T}$ cells into pro-inflammatory effector cells such as Th1 and Th17 [2,31]. In return, macrophages can receive activation signals from effector $\mathrm{T}$ cells to express high levels of reactive oxygen species, and so become superb killers of ingested micro-organisms [39]. By contrast, macrophages can also have anti-inflammatory roles and are involved in the resolution of inflammation, the phagocytosis of cellular debris, in wound healing (as described above) and the suppression of $\mathrm{T}$ cell proliferation [22]. Moreover, macrophages have many important non-immune roles in tissue development and homeostasis [61]. The phagocytic ability of macrophages is used to remove aged and apoptotic cells from the body [13], with the classical example being splenic macrophages that remove and phagocytose aged erythrocytes and neutrophils from the circulation [23]. Similarly the phagocytic activity of osteoclasts, a specialised macrophage found in the bone, has an important role in bone resorption, and an impairment in osteoclast function leads to osteopetrosis, a disease which results in skeletal fragility, despite increased bone mass [45]. Finally, microglia, the specialised macrophages of the central nervous system, have essential roles in the formation and maintenance of neural circuitry and brain structure [19]. How then can we explain this incredible heterogeneity in macrophage function? Recent advances reveal two sources of macrophage heterogeneity: diversity in ontogeny and activation.

\section{Macrophage heterogeneity: ontogeny}

Macrophages are unique in that they are the only immune cells derived from two developmental origins: progenitors that arise in the yolk sac and/or fetal liver during embryogenesis, and also from haematopoietic stem cells, which give rise to macrophage and dendritic cell precursors (MDP), and finally monocytes, throughout adulthood (Figure 1) [42]. Macrophages derived from embryonic precursors are known as tissue-resident macrophages (TRMs), as they are effectively seeded during the development of their respective tissue, and permanently reside throughout adulthood without limited renewal from haematopoietic precursors. Many different TRMs have now been identified and characterised, each with a specialised homeostatic function distinct to the tissue in which they reside. As mentioned above, brain-resident macrophages, known as microglia, are important in maintaining axonal excitability; lung-resident alveolar macrophages preserve surfactant 
homeostasis; liver-resident macrophages are Kupffer cells; Langerhans cells are macrophages resident in the skin and may have a key role in promoting immune tolerance $[18,42,44,52]$. TRMs have also been identified and characterised in the peritoneal cavity [29], gut [4], kidney [53], arterial wall [16], heart [17]. Recently, the transcriptional and regulatory network of a number of different TRMs has been extensively characterised [24,32]. This significant body of work demonstrated TRMs from different tissues have distinct transcriptional, enhancer and regulatory profiles. Strikingly, these profiles appear to be plastic and highly reliant on the microenvironment in which each TRM is located; the transcriptional profile of transplanted adult monocyte-derived macrophages is highly similar to those of embryonic TRMs, indicating an acquisition of TRMphenotype $[32,50]$.

By contrast, primarily during inflammatory responses, tissues are invaded by monocytederived macrophages in response to specialised cues. In homeostatic conditions, the principle driver of monocyte/macrophage differentiation is the cytokine, colony stimulating factor 1 (CSF-1, MCSF) (Figure 1) [25]. CSF-1 has pleotropic effects: it regulates the mobilisation of monocytes, and is a critical regulator of the differentiation, proliferation and survival of monocyte-derived tissue macrophages [25]. CSF-1 is not the only cytokine that can stimulate macrophage differentiation, for example under inflammatory conditions (like in the presence of IFN- $\gamma$ ); GM-CSF plays a critical role [26]. There are a number of different chemoattractants and adhesion molecules that drive the transmigration of monocytes into tissues from the vasculature. Here, TRMs play a key role as the initial immune cells to detect "danger" through their pattern recognition receptors, and their subsequent secretion of chemokines, such as CXCL2 and MIF [48]. Thus, to arrive in the tissues, blood-born monocytes must communicate with endothelium that has been activated by the release of chemoattractants (either from TRM or other cells within the tissue). Here, like other leucocytes, monocytes follow the general paradigm of the leucocyte adhesion cascade $[51,33]$. Monocytes use all 3 members of the selectin family, as well as the integrin $\alpha 4 \beta 1$ to initiate rolling on the inflamed vasculature. Inflammatory monocytes express the chemokine receptor CCR2 which recognises its ligands CXCL2 and MIF, and the subsequent activation of both $\alpha 4 \beta 1$ and $\beta 2$ integrins contributes to monocyte tight adhesion to the endothelium.

\section{Macrophage heterogeneity: activation}

Within the tissue, the presence of molecules including other cytokines, small metabolites, and foreign pathogens, can induce the further activation of monocyte-derived macrophages into functionally distinct subpopulations (Figure 1) [38]. Depending on the concentration and combination of stimuli, macrophages can be activated into a large spectrum of phenotypes; ranging 
from pro-inflammatory to anti-inflammatory effector functions. Macrophage function is therefore finely tuned to minute alterations in their local tissue microenvironment or milieu.

This heterogeneous spectrum of macrophage activation phenotypes was previously simplified into two discrete states: pro-inflammatory macrophages were referred to as "classically activated" or "M1", while anti-inflammatory were named "alternatively activated" or "M2". However, there is now consensus that this terminology of ' $\mathrm{M} 1$ ' and ' $\mathrm{M} 2$ ' is an oversimplification that does not reflect the complete heterogeneity of macrophage activation, particularly in vivo [38]. Hence, for in vitro studies, a new nomenclature system has been recently proposed whereby the stimuli used to activate is indicated in parentheses; for example, LPS-stimulated macrophages are described as "M(LPS)", IL-4-stimulated as "M(IL-4)", and so on [38]. No matter what macrophages are called, there is appreciation that it is not only the presence, but the phenotypic balance of pro- and anti-inflammatory macrophages within the tissue that is crucial to establishing an adequate amount of inflammation and wound healing, in response to alterations in homeostasis [9,34,47,60]. Generally, pro-inflammatory activated macrophages, for example those which encounter gram-positive bacterium or the cytokine interferon-gamma (IFN- $\gamma$ ), can be generally characterised as cells which secrete pro-inflammatory molecules leading to enhanced tissue inflammation and the activation of adaptive immunity (Figure 1). Conversely, anti-inflammatory macrophages, for example those which are stimulated with the cytokines IL-4 and IL-13, are generally considered to promote tissue homeostasis by suppressing inflammatory responses and enhancing tissue repair (Figure 1). Thus, understanding molecular mechanisms key for generating and maintaining the phenotype of pro- and anti-inflammatory activated macrophages may be potential therapeutic targets for diseases characterised by excessive inflammation or fibrosis.

\section{The renin-angiotensin system (RAS)}

\section{Beyond blood pressure regulation}

Well-recognised roles of the renin-angiotensin system (RAS) are the regulation of blood pressure, sodium retention and vasoconstriction. This is a highly regulated system, involving the concerted action of multiple organs, peptides and enzymes; others have reviewed this cascade in greater detail [3]. The end-product of the RAS is an 8-residue peptide, angiotensin II (Ang II). Ang II is the major active effector in the cascade, via its actions on the type 1 angiotensin receptor (AT1R).

Abnormal activation of the RAS, resulting in elevated and sustained levels of Ang II, is a recognised driver of hypertension and, subsequently, end-organ damage, and is a feature of diabetes-related complications such as retinopathy, nephropathy and neuropathy (hereafter collectively referred to as "RAS disorders"). While hypertension can drive these diseases and 
complications, therapeutic reduction of blood pressure does not completely prevent or cure patients of these disorders. Together, this has led to the idea that the RAS, and Ang II, has roles beyond those of blood pressure and water regulation; including both inflammation and fibrosis [5]. Increases in systemic levels of Ang II and/or activation of tissue-localised RAS, results in the expression of endothelial adhesive molecules such as integrins, selectins and vascular cell adhesion molecule 1 (VCAM1), and chemoattractants such as CXCL2; ultimately resulting in an infiltration of leucocytes, including monocytes, into the tissue [35,36,15,57,58]. Infiltrated leucocytes, including macrophages, are thought to then initiate the remodelling and fibrotic processes that lead to organ failure in these diseases. In light of recent insights into macrophage biology (as discussed above), it is important to re-examine how RAS and Ang II may affect macrophage homeostasis and lead to disease.

\section{Macrophages in RAS-disorders}

The infusion of Ang II into laboratory mice (usually C57B1/6 or Sv129 background) is a common experimental model which induces a robust and sustained increase in blood pressure, ultimately leading to kidney injury and cardiac hypertrophy (target organ-damage). In this model, a massive increase in macrophages is evident in the kidney, heart and vasculature [40,43,14,56]; generally, this is determined by immunohistochemistry for F4/80 (also known as EMR1) or CD68 (also known as ED1); so-called 'pan' markers of macrophages which are expressed at varying levels on all TRMs and monocyte-infiltrating macrophages, but also monocytes (Table 1).

Vascular damage and dysfunction, such as arterial remodelling and stiffening, are considered to be both a hallmark of, and, causative in the pathogenesis of hypertension [37]. As mentioned above, in murine models of hypertension such as Ang II infusion, a dramatic increase in the number of macrophages/monocytes into the vascular wall has been observed $[14,56]$. This is true also when hypertension is induced by high dietary salt in combination with deoxycorticosterone acetate (DOCA) [10]. The accumulation of macrophages/monocytes into vascular walls is subsequently associated with an elevation of inflammatory molecules and reactive oxygen species, eventually resulting in elevated vascular relaxation responses and the onset of hypertension $[14,56]$. A causative role for macrophages/monocytes has been demonstrated by their depletion and subsequent attenuation of vascular inflammation, dysfunction and overall hypertension: mice were generated to be devoid of macrophages due to CSF-1 deficiency [14], by inducible diphtheria toxin macrophage-specific depletion [56], or by with treatment with a chemical agonist of the macrophage-specific chemokine receptor, CCR2 [10]. Collectively, these studies indicate that targeting the infiltration and function of macrophages/monocytes in the vascular wall may be effective therapeutics against RAS-induced hypertension. 
Downstream of elevated blood pressure, the RAS additionally plays a role in the onset of socalled "end-organ damage" to tissues such as the kidney and heart. Here, as a result of Ang II infusion, an elevation in the number of macrophages is observed in both the kidney [43] and heart [40], resulting in inflammation and fibrosis, and eventual loss of organ function. The same is true for diabetes complications associated with aberrant RAS activation. For example, in our own work, we have shown a causative pathological role for elevations in retinal macrophage/microglia and the onset of diabetic retinopathy, which can be prevented by RAS inhibition [15,57,58].CCR2 knockout mice, which are deficient in monocytes, have a drastically reduced number of aortic-infiltrated macrophages in response to Ang II, resulting in attenuated fibrosis [8]. This finding indicated that Ang II may directly influence macrophage activation and function. To dissect this mechanism further in vivo, several groups have performed transplantation experiments with bone marrow from various knockout mice. For example, Crowley et al., investigated whether Ang II itself has a direct effect on immune cells, and performed transplantation studies with AT1R (the major Ang II receptor) deficient bone marrow $\left(\operatorname{Agtrl}^{-/}\right)$. This resulted in an augmented hypertensive response in mice transplanted with AT1R-deficient bone marrow and subjected to Ang II infusion, mediated by an increased number of $\mathrm{F} 4 / 80^{+}$myeloid cells in the kidney, suggesting that Ang II engagement with AT1R on macrophages restrains pro-inflammatory mechanisms [12]. Contrastingly, in a study of fibrosis-only kidney damage, unilateral ureteral obstruction (UUO), a divergence was observed in the number of $\mathrm{F} 4 / 80^{+}$myeloid cells and extent of kidney fibrosis. In this setting, AT1R deficiency restrained macrophage infiltration, but fibrosis was more pronounced [41]. Marko et al., investigated a down-stream signalling effect of Ang II-ATIR ligation by transplanting Bcl10 ${ }^{-/-}$bone marrow, which do not have an active CBM signalosome, thus inhibiting the activation of NF- $\mathrm{KB}$ pro-inflammatory pathways by Ang II [35]. Upon transfer of $\mathrm{Bcl10}^{-/-}$bone marrow and Ang II infusion, no difference in hypertension was observed, despite a reduction in monocyte/macrophage infiltration and attenuation of cardiac fibrosis [35]. Taken together, the precise and direct role of Ang II and other RAS components (not discussed here) on macrophage function and pathology remains unclear. We propose that recent advances in the surface phenotyping of macrophages, and thus, the degree of macrophage heterogeneity, may shed new light on the cellular mechanisms behind these above mentioned studies.

\section{Tissue resident versus monocyte-derived: which ones should we target?}

What has not yet been fully considered in the context of Ang II and target-organ damage is the respective contribution of TRMs versus monocyte-derived macrophages in mediating these diseases. This has been limited by the overuse of 'pan' macrophage markers like F4/80, which are expressed on both TRMs and monocyte-derived infiltrating macrophages, and to some extent on 
monocytes (Table 1). Advancements in the isolation of immune cells from tissues for analysis of flow cytometry has led to an increased understanding of the origin, identity and function of macrophages in tissues relevant to RAS disorders, including the kidney, heart and retina [24,32]. Recently, Epelman et al. identified four macrophage subsets within steady-state adult cardiac tissue that share the common surface expression of F4/80 and CD11b, but vary in the expression of the molecules MHC-II, Ly6c, CD64, MerTK, CD206 and CD11c (Table 1) [17]. While this may seem merely like immunological semantics, the authors further identified that these macrophage subsets have different origins (resident versus infiltrating), and subsequently altered mechanisms of turnover and function. Furthermore, Ang II infusion augmented proliferation of resident cardiac macrophage subsets (distinguished as $\mathrm{CCR}^{-}$) and infiltrated monocyte-derived macrophages (distinguished as $\mathrm{CCR}^{+}$); however, the amount of expansion varied between subsets; notably, infiltrating macrophage numbers $\left(\mathrm{CCR} 2^{+}\right)$increased at the expense of $\mathrm{CCR} 2^{-}$resident macrophages. This observation that tissue insult increases monocyte-infiltrating macrophages at the expense of TRMs has also been recently observed in studies of lung infection (Table 1) [7]. Epelman et al., also identified that functionally, resident cardiac macrophages were efficient immunosurveyors; phagocytosing dying cardiomyocytes and processing and presenting antigen via MHC-II. By contrast, $\mathrm{CCR} 2^{+}$monocyte-infiltrated macrophages expressed high levels of pro-inflammatory molecules, particularly those involved with the NLRP3 inflammasome [17]. Taken together, this significant work provides an explanation for why broad depletion of macrophages, (which target both monocyte and resident macrophages) are not protective. Instead, strategies should be developed to prevent monocyte influx, which in this setting appear to be the mediators of inflammation, while maintaining homeostatic tissue resident macrophage function.

Other tissues susceptible to Ang II-mediated inflammation and fibrosis include the kidney and retina; both of which have resident macrophages. Recently, in a model of type III hypersensitivity, kidney resident macrophages were shown to directly mediate a kidney inflammatory response upon detection of immune complexes (Table 1) [53]. Whether kidney resident macrophages mediate an inflammatory response upon RAS activation, or rather, the relative role of TRM versus monocyte-infiltrating macrophages upon RAS activation has not yet been directly assessed. However, in the UUO study by Nishida et al (described above, [41]), Agtr ${ }^{-/}$ macrophages were shown to have a reduced phagocytic ability, but a preserved oxidative capacity; indicating Ang II may play an important role in homeostatic kidney resident macrophage function. In the retina (and brain), microglia are the resident macrophage of interest. Microglia have been shown to seed the tissue extremely early in development [21], with strikingly no replenishment from monocyte-derived macrophages in adulthood [17] and instead, their numbers are maintained and expanded locally through proliferation $[1,49]$. In the context of retinopathy, we $[15,57,58]$ and 
others have observed an increased number of "microglia" upon RAS activation. However, commonly used markers such as Iba1, CD68 and F4/80 are expressed in both microglia and monocyte-derived macrophages. Furthermore, it is not clear whether microglia have the capacity to initiate inflammation and fibrosis like their monocyte-derived counterparts; in fact, there is mounting evidence that microglia do not share this capacity to become "activated" into specific phenotypes [46]. In light of recent advances in the demarcation of microglia from monocyteinfiltrating macrophages by flow cytometry (Table 1) [32], these models could be readdressed and, like the strategy of Epelman et al., the relative contribution of microglia and monocyte-derived macrophages in mediating retinal inflammation and damage can be distinguished.

\section{Macrophage activation in the context of RAS diseases}

As described above, the appearance of a 'macrophage' within a tissue can functionally mean a multitude of things; for example, this could be a resident macrophage maintaining tissue homeostasis by phagocytosing dying cells, or perhaps a monocyte-infiltrating macrophage clearing an intracellular pathogen. Thus, in order to understand the relative role of this 'macrophage' in mediating RAS diseases, identifying its phenotype is crucial. There has been a large reliance in the field on the "M1" and "M2" nomenclature, and the use of markers "specific" to these activation states. For example, CD206 (mannose receptor, MRC1), a C-type lectin important in phagocytosis and scavenging mannoglycoproteins, is a commonly used marker for anti-inflammatory "M2" macrophages. In vitro stimulation of bone-marrow derived macrophages with IL-4 and IL-13 does drive the increased surface expression of this protein. However, in vivo, it is also expressed on cardiac resident macrophages [17] and used as a general marker of human adipose tissue macrophages [62]. One would also expect pathogens which utilise the mannose metabolic pathway to alter macrophage surface expression of CD206. Conversely, nitric oxide synthase (iNOS) is used as a specific marker for pro-inflammatory "M1" macrophages, as it is significantly upregulated in macrophages stimulated with Th1 mediators such as lipopolysaccharides (LPS) and other endotoxins and the pro-inflammatory cytokine IFN- $\gamma$, and it is also robustly expressed on endothelial cells. Second, it is not known if Ang II infusion induces high tissue levels of endotoxins or "M1" and "M2" specific cytokines like IFN- $\gamma$ and IL-4, respectively. Thus, whether the respective "M1" and "M2" surface markers identified in vitro to be responsive to high concentrations of IL-4 and IFN- $\gamma$ alone, are similarly induced in vivo in response to a complex milieu of many cytokines in varying concentrations, is simply not known. This same question was asked by Kratz et al., who undertook a proteomics approach to identify surface markers of macrophages isolated from the adipose tissue or obese humans and mice [30]. Strikingly, "M1" markers which were induced upon stimulation with LPS and IFN- $\gamma$ (e.g. PD-L1, CD38) were absent 
from macrophages directly isolated from adipose tissue. Nonetheless, these adipose macrophages displayed a pro-inflammatory phenotype, as they demonstrated elevated expression of proinflammatory cytokines TNF- $\alpha$, IL1 $\beta$ and IL-6 [30]. In light of the numerous recent studies showing how distinct the transcriptional profiles of tissue resident macrophages are, it seems plausible that there would be changes in the panel of surface molecules expressed on pro- and anti-inflammatory macrophages within different tissues. Furthermore, in the setting of disease, the tissue milieu of cytokines, small metabolites [11,55] and even electrolytes [6,27,28], is highly likely to vary and thereby further modulate the response of the TRM or infiltrated-macrophage. In summary, there are likely to be multiple pathways which lead to the acquisition of a pro-inflammatory or pro-fibrotic macrophage phenotype, and these may differ substantially between tissues.

\section{Future directions}

We have highlighted here how recent advances in understanding macrophage heterogeneity may contribute to deciphering mechanisms in RAS-related diseases. We propose a first step being to move away from histology with 'pan' macrophage markers, and instead adopt flow cytometry to characterise the identity and function of resident versus infiltrating macrophages at different times of Ang II-induced disease; and in different tissues. However, a further challenge awaits in the characterisation of human myeloid cells, where, in contrast to the well characterised mouse macrophage populations, there is a profound lack of delineating surface markers for tissue resident versus infiltrating macrophages, and activated macrophages subsets [20]. Ultimately, if we can elucidate precisely which macrophage subsets are functionally important in driving inflammation and fibrosis characteristic of these RAS-associated diseases, we may be able to develop therapeutics to shift them towards non-disease causing subsets.

\section{Contributions and acknowledgements}

KJB and MDW wrote the manuscript. KJB is supported by a National Health and Medical Research Council of Australia Early Career Fellowship (APP1037633). 


\section{References}

1. Ajami B, Bennett JL, Krieger C, Tetzlaff W, Rossi FM (2007) Local self-renewal can sustain CNS microglia maintenance and function throughout adult life. Nat Neurosci 10:1538-1543. doi: $10.1038 / \mathrm{nn} 2014$

2. Arnold CE, Gordon P, Barker RN, Wilson HM (2015) The activation status of human macrophages presenting antigen determines the efficiency of Th17 responses. Immunobiology 220:10-19. doi:10.1016/j.imbio.2014.09.022

3. Atlas SA (2007) The renin-angiotensin aldosterone system: pathophysiological role and pharmacologic inhibition. J Manag Care Pharm 13:9-20. doi:10.18553/jmcp.2007.13.s8-b.9

4. Bain CC, Bravo-Blas A, Scott CL, Gomez Perdiguero E, Geissmann F, Henri S, Malissen B, Osborne LC, Artis D, Mowat AM (2014) Constant replenishment from circulating monocytes maintains the macrophage pool in the intestine of adult mice. Nat Immunol 15:929-937. doi:10.1038/ni.2967

5. Benigni A, Cassis P, Remuzzi G (2010) Angiotensin II revisited: new roles in inflammation, immunology and aging. EMBO Mol Med 2:247-257. doi:10.1002/emmm.201000080

6. Binger KJ, Gebhardt M, Heinig M, Rintisch C, Schroeder A, Neuhofer W, Hilgers K, Manzel A, Schwartz C, Kleinewietfeld M, Voelkl J, Schatz V, Linker RA, Lang F, Voehringer D, Wright MD, Hubner N, Dechend R, Jantsch J, Titze J, Muller DN (2015) High salt reduces the activation of IL-4- and IL-13-stimulated macrophages. J Clin Invest 125:4223-4238. doi:10.1172/JCI80919

7. Brown AS, Yang C, Fung KY, Bachem A, Bourges D, Bedoui S, Hartland EL, van Driel IR (2016) Cooperation between Monocyte-Derived Cells and Lymphoid Cells in the Acute Response to a Bacterial Lung Pathogen. PLoS Pathog 12:e1005691. doi:10.1371/journal.ppat.1005691

8. Bush E, Maeda N, Kuziel WA, Dawson TC, Wilcox JN, DeLeon H, Taylor WR (2000) CC chemokine receptor 2 is required for macrophage infiltration and vascular hypertrophy in angiotensin II-induced hypertension. Hypertension 36:360-363

9. Cao Q, Harris DC, Wang Y (2015) Macrophages in kidney injury, inflammation, and fibrosis. Physiology (Bethesda) 30:183-194. doi:10.1152/physiol.00046.2014 
10. Chan CT, Moore JP, Budzyn K, Guida E, Diep H, Vinh A, Jones ES, Widdop RE, Armitage JA, Sakkal S, Ricardo SD, Sobey CG, Drummond GR (2012) Reversal of vascular macrophage accumulation and hypertension by a CCR2 antagonist in deoxycorticosterone/salt-treated mice. Hypertension 60:1207-1212. doi:10.1161/HYPERTENSIONAHA.112.201251

11. Colegio OR, Chu NQ, Szabo AL, Chu T, Rhebergen AM, Jairam V, Cyrus N, Brokowski CE, Eisenbarth SC, Phillips GM, Cline GW, Phillips AJ, Medzhitov R (2014) Functional polarization of tumour-associated macrophages by tumour-derived lactic acid. Nature 513:559-563. doi:10.1038/nature13490

12. Crowley SD, Song YS, Sprung G, Griffiths R, Sparks M, Yan M, Burchette JL, Howell DN, Lin EE, Okeiyi B, Stegbauer J, Yang Y, Tharaux PL, Ruiz P (2010) A role for angiotensin II type 1 receptors on bone marrow-derived cells in the pathogenesis of angiotensin II-dependent hypertension. Hypertension 55:99-108. doi:10.1161/HYPERTENSIONAHA.109.144964

13. Dai XM, Ryan GR, Hapel AJ, Dominguez MG, Russell RG, Kapp S, Sylvestre V, Stanley ER (2002) Targeted disruption of the mouse colony-stimulating factor 1 receptor gene results in osteopetrosis, mononuclear phagocyte deficiency, increased primitive progenitor cell frequencies, and reproductive defects. Blood 99:111-120

14. De Ciuceis C, Amiri F, Brassard P, Endemann DH, Touyz RM, Schiffrin EL (2005) Reduced vascular remodeling, endothelial dysfunction, and oxidative stress in resistance arteries of angiotensin II-infused macrophage colony-stimulating factor-deficient mice: evidence for a role in inflammation in angiotensin-induced vascular injury. Arterioscler Thromb Vasc Biol 25:21062113. doi:10.1161/01.ATV.0000181743.28028.57

15. Deliyanti D, Miller AG, Tan G, Binger KJ, Samson AL, Wilkinson-Berka JL (2012) Neovascularization is attenuated with aldosterone synthase inhibition in rats with retinopathy. Hypertension 59:607-613. doi:10.1161/HYPERTENSIONAHA.111.188136

16. Ensan S, Li A, Besla R, Degousee N, Cosme J, Roufaiel M, Shikatani EA, El-Maklizi M, Williams JW, Robins L, Li C, Lewis B, Yun TJ, Lee JS, Wieghofer P, Khattar R, Farrokhi K, Byrne J, Ouzounian M, Zavitz CC, Levy GA, Bauer CM, Libby P, Husain M, Swirski FK, Cheong C, Prinz M, Hilgendorf I, Randolph GJ, Epelman S, Gramolini AO, Cybulsky MI, Rubin BB, Robbins CS (2016) Self-renewing resident arterial macrophages arise from embryonic CX3CR1(+) precursors and circulating monocytes immediately after birth. Nat Immunol 17:159168. doi:10.1038/ni.3343 
17. Epelman S, Lavine KJ, Beaudin AE, Sojka DK, Carrero JA, Calderon B, Brija T, Gautier EL, Ivanov S, Satpathy AT, Schilling JD, Schwendener R, Sergin I, Razani B, Forsberg EC, Yokoyama WM, Unanue ER, Colonna M, Randolph GJ, Mann DL (2014) Embryonic and adultderived resident cardiac macrophages are maintained through distinct mechanisms at steady state and during inflammation. Immunity 40:91-104. doi:10.1016/j.immuni.2013.11.019

18. Epelman S, Lavine KJ, Randolph GJ (2014) Origin and functions of tissue macrophages. Immunity 41:21-35. doi:10.1016/j.immuni.2014.06.013

19. Erblich B, Zhu L, Etgen AM, Dobrenis K, Pollard JW (2011) Absence of colony stimulation factor-1 receptor results in loss of microglia, disrupted brain development and olfactory deficits. PLoS One 6:e26317. doi:10.1371/journal.pone.0026317

20. Geissmann F, Gordon S, Hume DA, Mowat AM, Randolph GJ (2010) Unravelling mononuclear phagocyte heterogeneity. Nat Rev Immunol 10:453-460. doi:10.1038/nri2784

21. Ginhoux F, Greter M, Leboeuf M, Nandi S, See P, Gokhan S, Mehler MF, Conway SJ, Ng LG, Stanley ER, Samokhvalov IM, Merad M (2010) Fate mapping analysis reveals that adult microglia derive from primitive macrophages. Science 330:841-845. doi:10.1126/science. 1194637

22. Gordon S, Martinez FO (2010) Alternative activation of macrophages: mechanism and functions. Immunity 32:593-604. doi:10.1016/j.immuni.2010.05.007

23. Gordy C, Pua H, Sempowski GD, He YW (2011) Regulation of steady-state neutrophil homeostasis by macrophages. Blood 117:618-629. doi:10.1182/blood-2010-01-265959

24. Gosselin D, Link VM, Romanoski CE, Fonseca GJ, Eichenfield DZ, Spann NJ, Stender JD, Chun HB, Garner H, Geissmann F, Glass CK (2014) Environment drives selection and function of enhancers controlling tissue-specific macrophage identities. Cell 159:1327-1340. doi:10.1016/j.cell.2014.11.023

25. Hume DA, MacDonald KP (2012) Therapeutic applications of macrophage colony-stimulating factor-1 (CSF-1) and antagonists of CSF-1 receptor (CSF-1R) signaling. Blood 119:1810-1820. doi:10.1182/blood-2011-09-379214

26. Italiani P, Boraschi D (2014) From Monocytes to M1/M2 Macrophages: Phenotypical vs. Functional Differentiation. Front Immunol 5:514. doi:10.3389/fimmu.2014.00514 
27. Jantsch J, Binger KJ, Muller DN, Titze J (2014) Macrophages in homeostatic immune function. Front Physiol 5:146. doi:10.3389/fphys.2014.00146

28. Jantsch J, Schatz V, Friedrich D, Schroder A, Kopp C, Siegert I, Maronna A, Wendelborn D, Linz P, Binger KJ, Gebhardt M, Heinig M, Neubert P, Fischer F, Teufel S, David JP, Neufert C, Cavallaro A, Rakova N, Kuper C, Beck FX, Neuhofer W, Muller DN, Schuler G, Uder M, Bogdan C, Luft FC, Titze J (2015) Cutaneous Na+ storage strengthens the antimicrobial barrier function of the skin and boosts macrophage-driven host defense. Cell metabolism 21:493-501. doi:10.1016/j.cmet.2015.02.003

29. Kim KW, Williams JW, Wang YT, Ivanov S, Gilfillan S, Colonna M, Virgin HW, Gautier EL, Randolph GJ (2016) MHC II+ resident peritoneal and pleural macrophages rely on IRF4 for development from circulating monocytes. J Exp Med 213:1951-1959. doi:10.1084/jem.20160486

30. Kratz M, Coats BR, Hisert KB, Hagman D, Mutskov V, Peris E, Schoenfelt KQ, Kuzma JN, Larson I, Billing PS, Landerholm RW, Crouthamel M, Gozal D, Hwang S, Singh PK, Becker L (2014) Metabolic dysfunction drives a mechanistically distinct proinflammatory phenotype in adipose tissue macrophages. Cell metabolism 20:614-625. doi:10.1016/j.cmet.2014.08.010

31. Krausgruber T, Blazek K, Smallie T, Alzabin S, Lockstone H, Sahgal N, Hussell T, Feldmann M, Udalova IA (2011) IRF5 promotes inflammatory macrophage polarization and TH1-TH17 responses. Nat Immunol 12:231-238. doi:10.1038/ni.1990

32. Lavin Y, Winter D, Blecher-Gonen R, David E, Keren-Shaul H, Merad M, Jung S, Amit I (2014) Tissue-resident macrophage enhancer landscapes are shaped by the local microenvironment. Cell 159:1312-1326. doi:10.1016/j.cell.2014.11.018

33. Ley K, Laudanna C, Cybulsky MI, Nourshargh S (2007) Getting to the site of inflammation: the leukocyte adhesion cascade updated. Nat Rev Immunol 7:678-689. doi:10.1038/nri2156

34. Lumeng CN, Bodzin JL, Saltiel AR (2007) Obesity induces a phenotypic switch in adipose tissue macrophage polarization. J Clin Invest 117:175-184. doi:10.1172/JCI29881

35. Marko L, Henke N, Park JK, Spallek B, Qadri F, Balogh A, Apel IJ, Oravecz-Wilson KI, Choi M, Przybyl L, Binger KJ, Haase N, Wilck N, Heuser A, Fokuhl V, Ruland J, Lucas PC, McAllister-Lucas LM, Luft FC, Dechend R, Muller DN (2014) Bcl10 mediates angiotensin II- 
induced cardiac damage and electrical remodeling. Hypertension 64:1032-1039. doi:10.1161/HYPERTENSIONAHA.114.03900

36. Marko L, Kvakan H, Park JK, Qadri F, Spallek B, Binger KJ, Bowman EP, Kleinewietfeld M, Fokuhl V, Dechend R, Muller DN (2012) Interferon-gamma signaling inhibition ameliorates angiotensin II-induced cardiac damage. Hypertension 60:1430-1436. doi:10.1161/HYPERTENSIONAHA.112.199265

37. Mitchell GF (2014) Arterial stiffness and hypertension: chicken or egg? Hypertension 64:210214. doi:10.1161/HYPERTENSIONAHA.114.03449

38. Murray PJ, Allen JE, Biswas SK, Fisher EA, Gilroy DW, Goerdt S, Gordon S, Hamilton JA, Ivashkiv LB, Lawrence T, Locati M, Mantovani A, Martinez FO, Mege JL, Mosser DM, Natoli G, Saeij JP, Schultze JL, Shirey KA, Sica A, Suttles J, Udalova I, van Ginderachter JA, Vogel SN, Wynn TA (2014) Macrophage activation and polarization: nomenclature and experimental guidelines. Immunity 41:14-20. doi:10.1016/j.immuni.2014.06.008

39. Murray PJ, Wynn TA (2011) Protective and pathogenic functions of macrophage subsets. Nat Rev Immunol 11:723-737. doi:10.1038/nri3073

40. Nicoletti A, Heudes D, Mandet C, Hinglais N, Bariety J, Michel JB (1996) Inflammatory cells and myocardial fibrosis: spatial and temporal distribution in renovascular hypertensive rats. Cardiovasc Res 32:1096-1107

41. Nishida M, Fujinaka H, Matsusaka T, Price J, Kon V, Fogo AB, Davidson JM, Linton MF, Fazio S, Homma T, Yoshida H, Ichikawa I (2002) Absence of angiotensin II type 1 receptor in bone marrow-derived cells is detrimental in the evolution of renal fibrosis. J Clin Invest 110:1859-1868. doi:10.1172/JCI15045

42. Okabe Y, Medzhitov R (2016) Tissue biology perspective on macrophages. Nat Immunol 17:917. doi:10.1038/ni.3320

43. Ozawa Y, Kobori H, Suzaki Y, Navar LG (2007) Sustained renal interstitial macrophage infiltration following chronic angiotensin II infusions. Am J Physiol Renal Physiol 292:F330339. doi:10.1152/ajprenal.00059.2006

44. Perdiguero EG, Geissmann F (2016) The development and maintenance of resident macrophages. Nat Immunol 17:2-8. doi:10.1038/ni.3341 
45. Pollard JW (2009) Trophic macrophages in development and disease. Nat Rev Immunol 9:259270. doi:10.1038/nri2528

46. Ransohoff RM (2016) A polarizing question: do M1 and M2 microglia exist? Nat Neurosci 19:987-991. doi:10.1038/nn.4338

47. Ricardo SD, van Goor H, Eddy AA (2008) Macrophage diversity in renal injury and repair. J Clin Invest 118:3522-3530. doi:10.1172/JCI36150

48. Schiwon M, Weisheit C, Franken L, Gutweiler S, Dixit A, Meyer-Schwesinger C, Pohl JM, Maurice NJ, Thiebes S, Lorenz K, Quast T, Fuhrmann M, Baumgarten G, Lohse MJ, Opdenakker G, Bernhagen J, Bucala R, Panzer U, Kolanus W, Grone HJ, Garbi N, Kastenmuller W, Knolle PA, Kurts C, Engel DR (2014) Crosstalk between sentinel and helper macrophages permits neutrophil migration into infected uroepithelium. Cell 156:456-468. doi:10.1016/j.cell.2014.01.006

49. Schulz C, Gomez Perdiguero E, Chorro L, Szabo-Rogers H, Cagnard N, Kierdorf K, Prinz M, Wu B, Jacobsen SE, Pollard JW, Frampton J, Liu KJ, Geissmann F (2012) A lineage of myeloid cells independent of Myb and hematopoietic stem cells. Science 336:86-90. doi:10.1126/science.1219179

50. Scott CL, Zheng F, De Baetselier P, Martens L, Saeys Y, De Prijck S, Lippens S, Abels C, Schoonooghe S, Raes G, Devoogdt N, Lambrecht BN, Beschin A, Guilliams M (2016) Bone marrow-derived monocytes give rise to self-renewing and fully differentiated Kupffer cells. Nat Commun 7:10321. doi:10.1038/ncomms10321

51. Shi C, Pamer EG (2011) Monocyte recruitment during infection and inflammation. Nat Rev Immunol 11:762-774. doi:10.1038/nri3070

52. Shklovskaya E, O'Sullivan BJ, Ng LG, Roediger B, Thomas R, Weninger W, Fazekas de St Groth B (2011) Langerhans cells are precommitted to immune tolerance induction. Proc Natl Acad Sci U S A 108:18049-18054. doi:10.1073/pnas.1110076108

53. Stamatiades EG, Tremblay ME, Bohm M, Crozet L, Bisht K, Kao D, Coelho C, Fan X, Yewdell WT, Davidson A, Heeger PS, Diebold S, Nimmerjahn F, Geissmann F (2016) Immune Monitoring of Trans-endothelial Transport by Kidney-Resident Macrophages. Cell 166:9911003. doi:10.1016/j.cell.2016.06.058 
54. Steinman RM (1991) The dendritic cell system and its role in immunogenicity. Annu Rev Immunol 9:271-296. doi:10.1146/annurev.iy.09.040191.001415

55. Tannahill GM, Curtis AM, Adamik J, Palsson-McDermott EM, McGettrick AF, Goel G, Frezza C, Bernard NJ, Kelly B, Foley NH, Zheng L, Gardet A, Tong Z, Jany SS, Corr SC, Haneklaus M, Caffrey BE, Pierce K, Walmsley S, Beasley FC, Cummins E, Nizet V, Whyte M, Taylor CT, Lin H, Masters SL, Gottlieb E, Kelly VP, Clish C, Auron PE, Xavier RJ, O'Neill LA (2013) Succinate is an inflammatory signal that induces IL-1beta through HIF-1alpha. Nature 496:238242. doi:10.1038/nature11986

56. Wenzel P, Knorr M, Kossmann S, Stratmann J, Hausding M, Schuhmacher S, Karbach SH, Schwenk M, Yogev N, Schulz E, Oelze M, Grabbe S, Jonuleit H, Becker C, Daiber A, Waisman A, Munzel T (2011) Lysozyme M-positive monocytes mediate angiotensin II-induced arterial hypertension and vascular dysfunction. Circulation 124:1370-1381. doi:10.1161/CIRCULATIONAHA.111.034470

57. Wilkinson-Berka JL, Heine R, Tan G, Cooper ME, Hatzopoulos KM, Fletcher EL, Binger KJ, Campbell DJ, Miller AG (2010) RILLKKMPSV influences the vasculature, neurons and glia, and (pro)renin receptor expression in the retina. Hypertension 55:1454-1460. doi:10.1161/HYPERTENSIONAHA.109.148221

58. Wilkinson-Berka JL, Tan G, Binger KJ, Sutton L, McMaster K, Deliyanti D, Perera G, Campbell DJ, Miller AG (2011) Aliskiren reduces vascular pathology in diabetic retinopathy and oxygen-induced retinopathy in the transgenic (mRen-2)27 rat. Diabetologia 54:2724-2735. doi:10.1007/s00125-011-2239-9

59. Wynn TA (2008) Cellular and molecular mechanisms of fibrosis. J Pathol 214:199-210. doi:10.1002/path.2277

60. Wynn TA, Barron L (2010) Macrophages: master regulators of inflammation and fibrosis. Semin Liver Dis 30:245-257. doi:10.1055/s-0030-1255354

61. Wynn TA, Vannella KM (2016) Macrophages in Tissue Repair, Regeneration, and Fibrosis. Immunity 44:450-462. doi:10.1016/j.immuni.2016.02.015

62. Zeyda M, Wernly B, Demyanets S, Kaun C, Hammerle M, Hantusch B, Schranz M, Neuhofer A, Itariu BK, Keck M, Prager G, Wojta J, Stulnig TM (2013) Severe obesity increases adipose tissue expression of interleukin-33 and its receptor ST2, both predominantly detectable in 
endothelial cells of human adipose tissue. Int $\mathbf{J}$ Obes (Lond) 37:658-665. doi:10.1038/ijo.2012.118 


\section{Figure legends}

Figure 1. Tissue macrophages have heterogeneous mechanisms of ontogeny, activation and function. Tissue resident macrophages (TRMs) derived from embryonic precursors at the yolk sac or fetal liver stages, and thereafter populate their respective tissue throughout adulthood. Conversely, monocyte-derived macrophages are generated from haematopoietic stem cells, which lead to MDPs, which then derive circulating monocytes. CSF-1 regulates the mobilisation of monocytes, and their differentiation, proliferation and survival as tissue monocyte-derived macrophages. As sentinels of tissue homeostasis, when alterations are detected TRMs can secrete the chemoattractants CXCL2 and MIF that drive the invasion of monocytederived macrophages. Within the tissue, monocyte-derived macrophages can then further acquire a spectrum of phenotypes, depending on the combination and concentration of stimulatory cues such as pathogens and cytokines. Macrophages with a pro-inflammatory phenotype can have multiple functions, including the elimination of pathogens, and processing and presentation of antigen. Under disease settings (red font), excessive numbers and activation of pro-inflammatory macrophages can lead to chronic inflammation and the non-specific damage to organs. At the other end of the activation spectrum, macrophages with an antiinflammatory phenotype instead have functions including the repair and remodelling of tissue, and suppression of pro-inflammatory immune cells. In disease settings, such as the over activation of the reninangiotensin system, excessive anti-inflammatory macrophage activation can cause aberrant tissue repair, eventually resulting in fibrosis and loss of organ function. Abbreviations: MDP, monocyte and dendritic cell precursor; CSF-1, colony-stimulating factor 1; LPS, lipopolysaccharide; IFN- $\gamma$, interferon gamma; CXCL2, chemokine (C-X-C motif) ligand 2; MHC II, major histocompatibility complex class II; PD-L1, programmed death-ligand 1 or CD274; CD38, cyclic ADP ribose hydrolase; NO, nitric oxide; TNF- $\alpha$, tumour necrosis factor alpha; IL-1 $\beta$, interleukin 1-beta; IL-6, interleukin 6; PD-L2, programmed death-ligand 2 or CD273; Mrc1, mannose receptor; Arg1, arginase 1; Fizz1, resistin-like molecule alpha; Ym1, chitinaselike protein 3; Mgl2, macrophage galactose $\mathrm{N}$-acetyl-galatosamine specific lectin 2. 
Table 1. Summary of surface markers used to delineate tissue-resident (TRM) and monocyte-derived macrophages in murine tissues. Markers (functional description in brackets): CD45 (protein tyrosine phosphatase), CD11b (integrin, adhesion/migration), CD11c (integrin, adhesion/migration), Ly6C (14-17 kDa GPI-linked surface protein), Ly6G (21-35 kDa GPI-linked surface protein), F4/80 (EGF-TM7 family), MHC II (antigen presentation to $\mathrm{CD}^{+} \mathrm{T}$ cells), CD64 (IgG antibody Fc receptor), Clec4F (C-type lectin), SiglecF (Ig superfamily lectin), CD115 (macrophage colony stimulating factor receptor, CSF1R), ICAM2 (cell adhesion), GATA6 (transcription factor), CD103 (integrin, adhesion/migration), CCR2 (receptor for the chemokine CCL2/MCP-1), CX3CR1 (receptor for the chemokine CX3CL1/fractalkine), MerTK (receptor kinase), CD206 (mannose receptor), FceRI (IgE antibody Fc receptor). Abbreviations: lo, low surface expression; int, intermediate expression; hi, high expression; -, negative or no expression; +, positive expression; Auto, autofluorescence.

\begin{tabular}{|c|c|c|c|c|}
\hline & Tissue & Name & Surface markers & Ref. \\
\hline \multirow[t]{11}{*}{ TRMs } & Brain & Microglia & 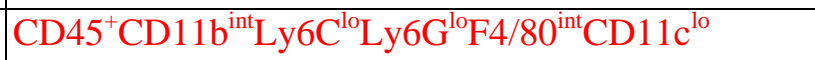 & {$[32]$} \\
\hline & Liver & Kupffer & $\mathrm{CD}_{4} 5^{+} \mathrm{CD} 11 \mathrm{~b}^{\mathrm{int}} \mathrm{F} 4 / 80^{+} \mathrm{MHCII}{ }^{\mathrm{hi}} \mathrm{CD} 64^{+} \mathrm{Clec} \mathrm{F}^{+}$ & {$[32,50]$} \\
\hline & Spleen & & $\mathrm{CD}^{2} 5^{+} \mathrm{CD} 11 \mathrm{~b}^{\text {int }} \mathrm{F} 4 / 80^{+} \mathrm{CD} 11 \mathrm{c}^{\text {int }} \mathrm{MHCII}{ }^{\text {int }}$ & [32] \\
\hline & Lung & Alveolar & $\mathrm{CD} 45^{+} \mathrm{CD} 11 \mathrm{~b}^{\text {lo/int }} \mathrm{F} 4 / 80^{+}$SiglecF $^{+} \mathrm{CD} 11 \mathrm{c}^{+} \mathrm{MHCII}^{\mathrm{I0}}$ & {$[7,32]$} \\
\hline & Peritoneum & Large & $\mathrm{CD} 115^{+} \mathrm{CD} 11 \mathrm{~b}{ }^{\text {hi }} \mathrm{F} 4 / 80^{+} \mathrm{ICAM}^{+} \mathrm{GATA}^{+}$ & {$[29,32]$} \\
\hline & & Small & $\mathrm{CD} 15^{+} \mathrm{CD} 11 \mathrm{~b}^{\mathrm{hi}} \mathrm{F} 4 / 80^{\mathrm{lo}} \mathrm{MHCII}^{+} \mathrm{GATA6}^{-}$ & {$[29,32]$} \\
\hline & $\begin{array}{c}\text { Gut } \\
\text { (Ileum/Colon) }\end{array}$ & & $\begin{array}{l}\mathrm{CD}^{+} 5^{+} \mathrm{MHCII}^{\mathrm{hi}} \mathrm{CD} 11 \mathrm{~b}^{+} \mathrm{CD} 11 \mathrm{c}^{+} \mathrm{CD} 103^{-} \\
\mathrm{CD}^{-} 4^{+} \mathrm{Ly}^{\mathrm{lo}} \mathrm{c}^{\mathrm{loint}}\end{array}$ & {$[32]$} \\
\hline & Heart & & $\mathrm{CD}^{2} 5^{+} \mathrm{Auto}^{+} \mathrm{CD}_{11 \mathrm{~b}}{ }^{+} \mathrm{F} 4 / 80^{+}$CCR2-MHCII ${ }^{\text {hi }}$ & {$[17]$} \\
\hline & & & 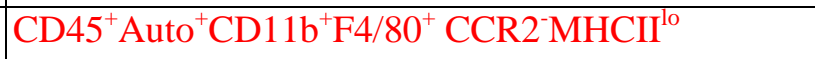 & {$[17]$} \\
\hline & & & $\mathrm{CD}^{2} 5^{+}$Auto $^{+} \mathrm{CD} 11 \mathrm{~b}^{+} \mathrm{F} 4 / 80^{+}$CCR2 Ly6C $^{+}$ & {$[17]$} \\
\hline & Kidney & & $\mathrm{CD}^{2} 5^{+} \mathrm{F} 4 / 80^{\mathrm{hi}} \mathrm{MHCII}^{+} \mathrm{CX} 3 \mathrm{CR} 1^{+} \mathrm{CD} 11 \mathrm{c}^{+} \mathrm{CCR} 2^{-}$ & {$[53]$} \\
\hline Monocytes & Blood/Tissue & & CD115 ${ }^{+}$CD11b+Ly6C inthi $^{\text {in }}$ 6y-F4/80 $0^{\text {Io/int }}$ & {$[32]$} \\
\hline \multirow[t]{2}{*}{ Neutrophils } & Blood/Tissue & & 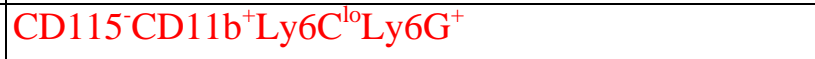 & {$[32]$} \\
\hline & & Insult & & \\
\hline \multirow{2}{*}{$\begin{array}{l}\text { Monocyte- } \\
\text { derived } \\
\text { macrophages }\end{array}$} & Heart & Ang II infusion & $\begin{array}{l}\mathrm{CD} 45^{+} \text {Auto }^{+} \mathrm{CD} 11 \mathrm{~b}^{+} \mathrm{F} 4 / 80^{+} \mathrm{CCR} 2^{+} \mathrm{MHCII}^{\mathrm{hi}} \mathrm{MerTK}^{+} \\
\mathrm{CD}^{+} 4^{+} \mathrm{CD} 11 \mathrm{c}^{\text {hi }} \mathrm{CD} 206^{+}\end{array}$ & {$[17]$} \\
\hline & Lung & $\begin{array}{l}\text { L.pneumophilia } \\
\text { infection }\end{array}$ & 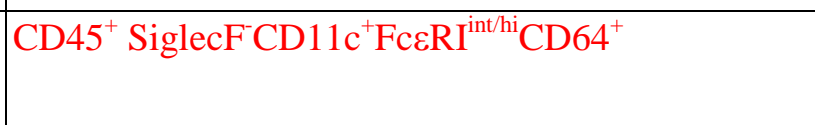 & {$[7]$} \\
\hline
\end{tabular}




\begin{tabular}{llll}
\hline & Specialized function \\
\hline
\end{tabular}

